\title{
Pengembangan Buku Ajar Ipa Berbasis Peta Pikiran untuk Melatih Berpikir Kreatif Peserta Didik di Sekolah Dasar
}

\author{
Rian Ningsih Pramunita \\ Universitas Negeri Surabaya \\ rianningsihpramunita@gmail.com
}

\begin{abstract}
Abstrak
Penelitian ini bertujuan untuk menghasilkan produk berupa buku ajar yang berbasis peta pikiran untuk melatih berpikir kreatif peserta didik di sekolah dasar. Materi yang di kembangkan adalah materi pengaruh kalor terhadap benda yang terdapat pada materi kelas V di Sekolah Dasar. Metode penelitian yang digunakan adalah metode penelitian pengembangan dengan mengacu pada model 4D yang mempunyai tahapan yaitu, (1) pendefinisian, (2) perancangan, (3) pengembangan, (4) penyebaran. Desain ujicoba menggunakan One Group Pre-test Post-test Design. Teknik analisis data menggunakan analisis data deskriptif kuantitatif. Insturmen yang digunakan antaranya lembar validasi, lembar tes, dan kuesioner. Buku ajar yang dikembangkan dinyatakan memenuhi kriteria valid pada komponen kelayakan isi, kelayakan penyajian, kelayakan kebahasaan dan ke grafikan. Buku ajar yang dikembangkan juga dinyatakan sebagai buku ajar yang praktis di tinjau dari respon peserta didik. Buku ajar yang dikembangkan juga dinyatakan efektif ditinjau dari keterampilan berpikir kreatif yang meningkat dari pretest yang memeroleh presentase sebesar 28\% meningkat pada post-test menjadi 58,2\% dengan $\mathrm{N}$-gain ketuntasan kategori sedang. Berdasarkan pembahasan hasil dan temuan-temuan disimpulkan bahwa buku ajar IPA berbasis peta pikiran yang telah dikembangkan pada materi pengaruh kalor terhadap benda layak digunakan untuk melatih berpikir kreatif peserta didik di Sekolah Dasar.
\end{abstract}

Kata kunci: Buku Ajar, Peta Pikiran, Berpikir Kreatif.

\begin{abstract}
This research aims to produce a mind-based teaching book product to train the creative thinking of learners in elementary school. The material developed is the heat influence material of the objects contained in the fifth-grade material in elementary school. The research method used is the development research method with reference to the model $4 D$ which has a stage that is, (1) definition, (2) design, (3) development, (4) dissemination. Trial design using One Group Pre-Test Post-Test Design. Data analysis techniques using quantitative descriptive data analysis. The instruments used include validation sheets, test sheets, and questionnaires. The teaching books developed is stated to meet the valid criteria on the content eligibility components, presentability, eligibility and the feasibility of the graphic. The developed teaching books are also a practical teaching book reviewed from the learners' response. Developed teaching books are also effectively reviewed from the increased creative thinking skills of a pre-test that has a percentage of $28 \%$ increased in post-test to $58.2 \%$ with $\mathrm{N}$-gain in the moderate category. Based on the discussion of the results and findings concluded that the natural sciences teaching books based on mind maps that have been developed on the material of the heat influence to the object deserves to be used to train creative thinking students in elementary school.
\end{abstract}

Keywords: Teaching books, mind maps, creative thinking.

https://doi.org/.

Copyright $($ 2021, Rian Ningsih Pramunita This is an open-access article under the CC-BY License. 


\section{PENDAHULUAN}

Membentuk peserta didik dengan keterampilan berpikir kreatif tentunya bukanlah hal mudah dan singkat, peserta didik memerlukan pembiasaan untuk melatih kemampuan berpikir kreatif tersebut melalui pendidikan formal sekolah maupun dikehidupan sehari-hari. Pendidikan sepatutnya terarah pada pengembangan kemampuan kreativitas peserta didik supaya nantinya dapat menjadi pemenuh kebutuhan pribadi, masyarakat, dan negara (Munandar, 2014). Untuk mewujudkan keterampilan berpikir kreatif pada peserta didik, maka kemampuan untuk berpikir kreatif perlu digabungkan ke dalam mata pelajaran.

Kemampuan berpikir kreatif menjadi keahlian yang wajib dimiliki oleh manusia dalam hal ini peserta didik. Pernyataan tersebut didukung oleh (Munandar, 2014) yang mengatakan jika kemajuan teknologi mengharuskan setiap individu agar mampu menyesuaikan diri dengan kreatif, kreativitas atau daya cipta membuat seseorang untuk menemukan penemuan baru di bidang ilmu serta bidang lain yang akan berguna bagi manusia. Keterampilan berpikir kreatif di Indonesia sendiri telah diintegrasikan dalam kurikulum pendidikan UU NO. 20 tahun 2003 pasal 3 tentang Sistem Pendidikan Nasional yang bertujuan untuk berkembangnya potensi peserta didik agar menjadi manusia yang beriman dan bertakwa kepada Tuhan Yang Maha Esa, berakhlak mulia, sehat, berilmu, cakap, mandiri, dan menjadi warga negara yang demokratis serta bertanggung jawab (Depdikbud, 2013).

Namun fakta yang banyak dijumpai di lapangan adalah masih banyak pelaksanaan pembelajaran yang hanya berfokus pada rana kognitif peserta didik dan kurang memunculkan keterampilan berpikir kreatif (Insyasiska, 2017). Kenyataan tersebut senada hasil pengamatan yang telah dilaksanakan peneliti di SDN Kembangringgit 03 Mojokerto. Hasil observasi yang dilihat dalam buku ajar materi pengaruh kalor terhadap benda, proses pembelajaran, dan evaluasi pembelajaran belum menjangkau rana berpikir kreatif.

Berdasarkan hasil observasi peneliti ke sekolah yang dituju ditemukan bahwa kualitas buku ajar pada materi pengaruh kalor terhadap benda yang diguanakan terkesan kurang membantu peserta didik dalam melatih berpikir kreatif khususnya pada materi pengaruh kalor terhadap benda, serta tidak terdapat indikator berpikir kreatif yang ingin dicapai. Penjelasan itu senada dengan pernyataan (Sholahuddin, 2011) yang menjeslaskan jika buku ajar pada umumnya hanya menekankan pada materi tanpa mempelajari cara peserta didik dalam memahami materi. Oleh sebab itu, diperlukan suatu perbaikan buku ajar yang efektif guna melatih kemampuan berpikir kreatif peserta didik sebagaimana yang dikemukakan oleh (Mulyasa, 2006) di mana buku ajar mengandung pesan pembelajaran.

Keberadaan buku ajar yang baik dibutuhkan khususnya pada materi pengaruh kalor terhadap benda, peserta didik cenderung merasa kesulitan dalam mempelajari materi tersebut bila dibandingkan materi yang lain (Ma'rifah, dkk, 2016). Pembelajaran yang diharapkan mampu melatih kemampuan berpikir kreatif sangat diperlukan. Salah satu model pembelajaran dapat diterapkan untuk melatih berpikir kreatif peserta didik ialah peta pikiran. Peta pikiran adalah teknik mencatat efektif, kreatif, sekaligus secara langsung memetakan pikiran-pikiran kita (Buzan, 2015), senada dengan itu (Widura, 2016) mengungkapkan Peta pikiran (Mind Map) ialah sebuah teknik yang membuat kita untuk menggali seluruh kemampuan otak guna kepentingan berpikir dan belajar.

Hubungan antara peta pikiran dengan berpikir kreatif seperti halnya hubungan sebab dan akibat. Karakteristik peta pikiran yang berfokus pada pemanfaatan otak secara maksimal yang akan menjadi alat pemikir yang kreatif dan menghasilkan ide-ide yang baru, orisinil, dan berbeda. Kemampuan berpikir kreatif akan terlatih ketika peseta didik membuat peta pikiran dengan menghasilkan kata-kata kunci yang digunakan dalam 
membuat cabang-cabang yang sesuai (kelancaran/fluency), menghasilkan ide yang beragam (luwes/fleksibility), dan menghasilkan ide yang tak biasa diantara kebiasa atau baru (originality).

Beberapa hasil penelitian sebelumnya yang senada dengan penilaian ini di antaranya adalah (Polat, 2017) yang mengatakan bahwa anak-anak yang bekerja dengan peta pikiran lebih berhasil dalam pengembangkan keterampilan IPA bila dibandingkan dengan anak-anak yang belajar tanpa menggunakan peta pikiran, sementara (Balim, 2003) mengatakan bahwa peta pikiran untuk pembelajaran IPA akan membantu membantu peserta didik dalam belajar dengan cara membuat mereka mengkorelasikan banyak konsep. Hal senada terdapat dalam penelitian (Malycha, 2017) yang mendapatkan hasil jika teknik peta acak yaitu gabungan pemetaan pikiran dan teknik kombinasi konseptual mampu untuk menumbuhkan potensi kreatif peserta didik.

Berdasarkan penjabaran di atas, perlu adanya wadah yang mampu dijadikan sebagai alat dalam mengaplikasikannya di antaranya ialah melalui pengembangan buku ajar. Pengembangan buku ajar dengan berbasis peta pikiran dirasa sesuai untuk melatih berpikir kreatif peserta didik dengan langkah-langkah model pembelajaran berbasis peta pikiran yang memberikan peserta didik wadah untuk melatih berpikir kreatif. Maka, penulis memandang penting melaksanakan penelitian dengan tujuan membuat buku ajar IPA berbasis peta pikiran untuk melatih berpikir kreatif peserta didik di sekolah dasar.

\section{METODE PENELITIAN}

Penelitian ini adalah merupakan penelitian pengembangan dengan hasil akhir berupa buku ajar IPA berbasis peta pikiran untuk melatih berpikir kreatif peserta didik di Sekolah Dasar. Penelitian ini dilakukan pada bulan Januari sampai dengan April 2020 pada semester genap tahun ajaran 2019//2020. Penelitian dilakukan dengan mendatangi rumah sebagain peserta didik kelas 5 di Sekolah Dasar. Subjek penelitian ini adalah buku ajar IPA berbasis peta pikiran untuk melatih berpikir kreatif peserta didik kelas V Sekolah Dasar dengan materi "Pengaruh Kalor terhadap Benda" beserta perangkat pembelajaran yang meliputi RPP (Rencana Pelaksanaan Pembelajaran), dan tes berpikir kreatif peserta didik.

Penelitian ini termasuk ke dalam bentuk penelitian pengembangan. Pengembangan yang dilakukan adalah pengembangan buku ajar IPA berbasis peta pikiran dengan menggunakan model 4D yang akan diujicoba pada peserta didik kelas V sekolah dasar. Dalam model ini terdapat empat tahapan yaitu define (pendefinisian), design (perancangan), development (pengembangan), dan disseminate (penyebaran) tetapi pada penelitian ini, peneliti hanya menggunakan 3 tahapan pengembangan di karenakan tujuan dari pengembangan ini hanya untuk mengatahui kelayakan buku ajar sehingga pengembangan dianggap selesai pada tahap uji coba produk tidak menyebarluaskan produk. 


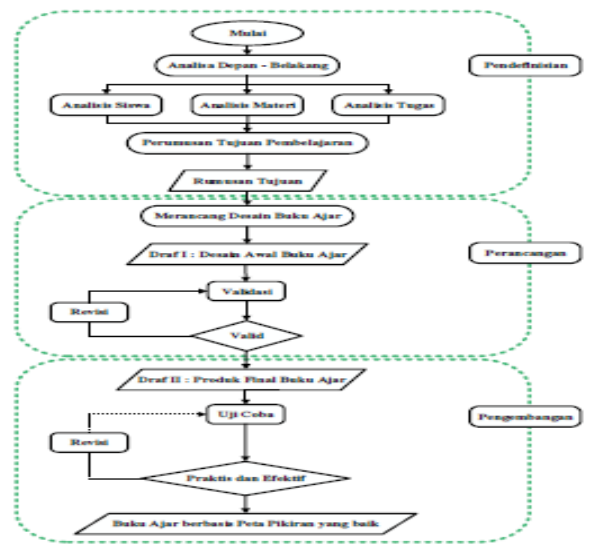

\section{Gambar 1. Alur Pengembangan Buku Ajar Model 4D (Diadaptasi dari Ibrahim, 2015)}

\section{HASIL DAN PEMBAHASAN}

Hasil penelitian pengembangan buku ajar IPA berbasis peta pikiran untuk melatih berpikir kreatif peserta didik kelas 5 Sekolah Dasar akan didiskusikan pada bab ini. Pengembangan buku ajar dapat diartikan sebagai proses terbentuknya sistem pengajaran yang tersusun secara sistematis, efektif, dan efisien dengan cara mengidentifikasi masalah, mengembangkan, dan mengevaluasi untuk peningkatakan kemampuan peserta didik (Suparman, 2012).

\section{Format Buku Ajar}

Format buku ajar IPA berbasis peta pikiran disesuaikan dengan standar penyusunan buku yang sudah ditentukan oleh BSNP. Namun, buku ajar IPA berbasis peta pikiran dikembangkan dengan memuat langkah-langkah pembelajaran menggunakan peta pikiran yang bertujuan dapat melatihkan keterampilan berpikir kreatif peserta didik.

Buku ajar IPA berbasis peta pikiran dikembangkan memiliki format yang terdiri atas tiga bagian yaitu bagaian awal, bagian isi, dan bagian penutup. Beberapa bagian pada awal buku terdiri atas sampul depan, kata pengantar, fitur buku, daftar isi, peta konsep, dan tujuan pembelajaran. Bagian isi terdiri atas materi pembelajaran, lembar kerja praktikum, lembar kerja peta pikiran dan soal evaluasi. Sedangkan untuk bagian akhir terdiri atas rangkuman, daftar pustaka, dan sampul belakang.

Ukuran buku ajar yang dikembangkan adalah A4 dengan ukuran 210x297 mm yang mengacu standar penyusunan buku oleh BNSP. Pemilihan buku disesuaikan dengan materi dan pembelajaran dengan menggunakan peta pikiran. Materi isi disesuaikan dengan tingkat perkembangan kognitif peserta didik. Keadaan ini yang nantinya akan mempengaruhi ketebalan dan tata letak bagian isi.

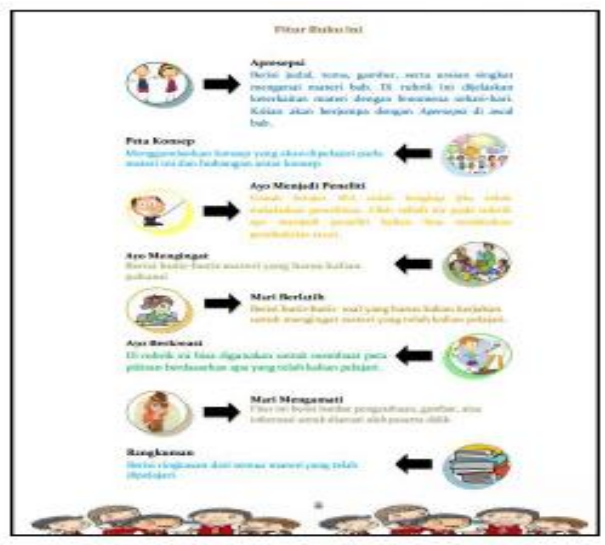

Gambar 2. Fitur - Fitur di dalam Buku Ajar 


\section{Validitas Buku Ajar}

Buku ajar dapat dikatakan baik apabila memenuhi empat aspek kelayakan yaitu isi, penyajian, kebahasaan, dan kegrafikan (BSNP, 2007). Guna dapat mengembangkan buku ajar yang memenuhi empat komponen kelayakan, maka digunakan instrumen validasi buku ajar IPA berbasis peta pikiran.

Buku ajar IPA berbasis peta pikiran perlu divalidasi supaya mendapatkan informasi yang ingin diperoleh melalui instrumen yang dikembangkan (Fraenkel, 2011). Buku ajar IPA berbasis peta pikiran di validasi oleh dua orang validator yang terdiri dari ahli materi dan ahli desain. Validator memberikan masukan yang dianggap penting sehingga kekurangan dalam buku ajar dapat disempurnakan sesuai saran dari validator.

Tabel 1. Rekapitulasi Modus Ktegori Kelayakan Tiap Komponen Validitas

\begin{tabular}{|l|l|c|}
\hline No. & \multicolumn{1}{|c|}{ Komponen Kelayakan } & Modus kategoi kelayakan \\
\hline 1. & Relayakan Ii & Sangat Valid \\
\hline 2. & Relayakan Penyajan & Valid \\
\hline 3. & Kelayakan Kebahasaan & Valid \\
\hline 4. & Relayakan Kegafikan & Valid \\
\hline Modus ketegoi kelayakan bukn ajar & Valid \\
\hline
\end{tabular}

Aspek selanjutnya yang menjadi tolak ukur validitas buku ajar IPA berbasis peta pikiran yang dikembangkan adalah uji keterbacaan dari materi yang terdapat dalam buku ajar. Uji keterbacaan pada buku ajar yang dikembangkan menggunakan formula grafik fry untuk mengetahui keterbacaan dari suatu waca diambil 100 kata dari wacana yang dianggap representatif yang kemudian dihitung jumlah kalimat dan suku kata serta mencocokkannya dengan grafik fry.

Tabel 2. Rekapitulasi Uji Keterbacaan

\begin{tabular}{|c|c|c|c|c|c|}
\hline $\begin{array}{c}\text { Wacana } \\
\text { Sampel }\end{array}$ & $\begin{array}{c}\text { Jumlah } \\
\text { Suku } \\
\text { Kata }\end{array}$ & $\begin{array}{c}\text { Jumlah } \\
\text { Kalimat }\end{array}$ & $\begin{array}{c}\text { Penetapan } \\
\text { Tingkat } \\
\text { Kelas } \\
\text { Keterbacaan } \\
\text { Penerapan } \\
\text { Buku Ajar }\end{array}$ & $\begin{array}{c}\text { Penetapan } \\
\text { Tingkat Kelas } \\
\text { Keterbacaan } \\
\text { Penerapan } \\
\text { Buku Ajar }\end{array}$ & Kategori \\
\hline 1 & 133,2 & 7,4 & 5 & $5,6,7$ & Sesuai \\
\hline 2 & 140,4 & 8,8 & 5 & $5,6,7$ & Sesuai \\
\hline 3 & 147,6 & 11,3 & 5 & $5,6,7$ & Sesuai \\
\hline \multicolumn{7}{|c|}{ Modus kategon keterbacaan } & Sesuai \\
\hline
\end{tabular}

\section{Kepraktisan Buku Ajar}

Buku ajar IPA berbasis peta pikiran yang dikembangkan dapat dinyatakan praktis ditinjau dari respon peserta didik setelah mengikuti pembelajaran yang didapatkan dari pengisian angket respon peserta didik. Angket respon ini diisi oleh 11 peserta didik. Hasil angket respon peserta didik didapatkan dari jumlah peserta didik yang menjawab "Ya" pada setiap pertanyaan.

Dari 9 pertanyaan angket, didapatkan modus presentase dengan kategori baik. Maka, dapat disimpulan bahwa buku ajar IPA berbasis peta pikiran yang dikembangkan mendapatkan respon baik dari peserta didik di mana meraka merasa pembelajaran lebih mudah dan dapat melatih berpikir kreatif.

\section{Keefektifan Buku Ajar}

Buku ajar IPA berbasis peta pikiran yang dikembangkan dinyatakan efektif apabila buku ajar tersebut dapat dipergunakan sebagai alat pelancar ketercapaian tujuan 
pembelajaran (Muslich, 2010). Guna mendapatkan data tentang ketercapaian tujuan pembelajaran maka dilakukan dengan memberikan soal pre-test dan post-tes.

Tabel 3. Data Pre-Test Keterampilan Berpikir Kreatif

\begin{tabular}{|c|c|c|c|c|}
\hline \multirow{2}{*}{$\begin{array}{c}\text { Nama Peserta } \\
\text { Didik }\end{array}$} & \multicolumn{3}{|c|}{ Indikator } & \multirow{2}{*}{ Jumlah } \\
\cline { 2 - 4 } & Lancar & Luwes & Orisinil & \\
\hline RA & 12 & 8 & 0 & 20 \\
\hline FA & 8 & 8 & 0 & 16 \\
\hline SEA & 20 & 12 & 4 & 36 \\
\hline PVOS & 12 & 8 & 0 & 20 \\
\hline TFH & 16 & 8 & 8 & 32 \\
\hline AZ & 12 & 16 & 0 & 28 \\
\hline SAPK & 12 & 8 & 8 & 28 \\
\hline FA & 16 & 8 & 0 & 24 \\
\hline S & 12 & 8 & 4 & 24 \\
\hline MA & 24 & 16 & 8 & 48 \\
\hline MAH & 16 & 4 & 12 & 32 \\
\hline Rata-rata & $\mathbf{1 4 , 5}$ & $\mathbf{9 , 5}$ & $\mathbf{4}$ & 28 \\
\hline
\end{tabular}

Tabel 4. Data Post-Test Keterampilan Berpikir Kreatif

\begin{tabular}{|c|c|c|c|c|}
\hline \multirow{2}{*}{$\begin{array}{c}\text { Nama Peserta } \\
\text { Didik }\end{array}$} & \multicolumn{3}{|c|}{ Indikator } & \multirow{2}{*}{ Jumlah } \\
\cline { 2 - 4 } & Lancar & Luwes & Orisinil & \\
\hline RA & 20 & 8 & 12 & 40 \\
\hline FA & 16 & 24 & 20 & 60 \\
\hline SEA & 24 & 28 & 24 & 76 \\
\hline PVOS & 12 & 16 & 8 & 36 \\
\hline TFH & 24 & 12 & 16 & 52 \\
\hline AZ & 20 & 20 & 12 & 52 \\
\hline SAPK & 16 & 20 & 16 & 52 \\
\hline FA & 16 & 24 & 20 & 60 \\
\hline S & 32 & 24 & 8 & 64 \\
\hline MA & 28 & 24 & 12 & 64 \\
\hline MAH & 24 & 32 & 28 & 84 \\
\hline Rata-rata & $\mathbf{2 1 , 1}$ & $\mathbf{2 1 , 1}$ & $\mathbf{1 6}$ & 58,2 \\
\hline
\end{tabular}

Tabel 5. Pencapaian Indikator Berpikir Kreatif

\begin{tabular}{|c|c|c|c|c|c|c|}
\hline \multirow{3}{*}{$\begin{array}{c}\text { Nama } \\
\text { Peserta } \\
\text { didik }\end{array}$} & \multicolumn{6}{|c|}{ Indikator } \\
\hline & \multicolumn{2}{|c|}{ Lancar } & \multicolumn{2}{|c|}{ Luwes } & \multicolumn{2}{|c|}{ Orisinil } \\
\hline & Pre & Post & Pre & Post & Pre & Post \\
\hline RA & 12 & 20 & 8 & 8 & 0 & 12 \\
\hline FA & 8 & 16 & 8 & 24 & 0 & 20 \\
\hline SEA & 20 & 24 & 12 & 28 & 4 & 24 \\
\hline PVOS & 12 & 12 & 8 & 16 & 0 & 8 \\
\hline TFH & 16 & 24 & 8 & 12 & 8 & 16 \\
\hline$A Z$ & 12 & 20 & 16 & 20 & 0 & 12 \\
\hline SAPK & 12 & 16 & 8 & 20 & 8 & 16 \\
\hline FA & 16 & 16 & 8 & 24 & 0 & 20 \\
\hline $\mathrm{S}$ & 12 & 32 & 8 & 24 & 4 & 8 \\
\hline MA & 24 & 28 & 16 & 24 & 8 & 12 \\
\hline MAH & 16 & 24 & 4 & 32 & 12 & 28 \\
\hline Kategori & \multicolumn{2}{|c|}{$\begin{array}{c}\text { N-gain } 0,45 \\
\text { (Sedang) }\end{array}$} & \multicolumn{2}{|c|}{$\begin{array}{c}\mathrm{N} \text {-gain } 0,44 \\
\text { (Sedang) }\end{array}$} & \multicolumn{2}{|c|}{$\begin{array}{c}\mathrm{N} \text {-gain } 0,47 \\
\text { (Sedang) }\end{array}$} \\
\hline
\end{tabular}

\section{KESIMPULAN DAN SARAN}

Kesimpulan berdasarkan pembahasan di atas dapat disimpulkan bahwa buku ajar IPA berbasis peta pikiran dapat digunakan untuk melatih berpikir kreatif peserta didik dalam kegiatan pembelajaran. Dengan demikian, pertanyaan peneliti telah terjawab bahwa buku ajar yang dikembangkan efektif untuk diterapkan. Berdasarkan uraian yang telah diberikan, buku ajar IPA berbasis peta pikiran yang telah dikembangkan secara keseluruhan telah memenuhi kriteria kelayakan valid berdasarkan hasil validasi tiap komponen kelayakan buku ajar, buku ajar IPA berbasis peta pikiran untuk melatih 
berpikir kreatif telah memenuhi kriteria praktis berdasarkan angket respon peserta didik dengan modus kategori baik, dan efektif berdasarkan berdasarkan hasil tes berpikir kreatif peserta didik yang menunjukkan terjadinya peningkatan dari pre-test ke post-tes. Data pre-test peserta didik memeroleh presentase sebesar 28\% dan meningkat pada post-test menjadi 58,2\%. Nilai $\mathrm{N}$-gain masing-masing indikator dan ketuntasan hasil belajar memeroleh nilai dengan kategori sedang.

Berdasarkan pengalaman selama penelitian dan simpulan di atas, maka saran yang dapat dikemukakan diantaranya perlu adanya pengembangan buku ajar berbasis peta pikiran pada materi dan mata pelajaran lain, diperlukan pengolahan waktu dan persiapan yang baik dalam penerapan pembelajaran menggunakan buku ajar berbasis peta pikiran agar pembelajaran dapat berjalan dengan efisien dan efektif, sehingga peserta didik memiliki banyak kesempatan dalam melatih kemampuan berpikir kreatif, dan pengembangan buku ajar berbasis peta pikiran perlu ditindaklanjuti dengan penyebaran lebih luas, yaitu dengan menyebarkan ke Sekolah Dasar-Sekolah Dasar lainnya sehingga hasil pengembangan buku ajar bisa lebih baik.

\section{UCAPAN TERIMAKASIH}

Terimakasih kepada Bapak dan Ibu Pembimbing, Bapak dan Ibu Validator, Bapak dan Ibu Guru SDN Kembangringgit 03, siswa siswi SDN Kembangringgit 03, dan semua pihak yang terlibat dalam penelitian ini.

\section{REFERENSI}

Badan Nasional Sertifikasi Profesi 2007.

Fraenkel, J. R., Wallen, N. E., \& Hyun, H. H. 2011. How To Design And Evaluate Research In Educatian. New York: McGraw-Hill Humanities/Social Sciences/Languages.

Ibrahim, Muslimin. 2015. Matari Pokok Pengembangan Kurikulum dan Pembelajaran Biologi. Tanggerang Selatan: Universitas Terbuka.

Ibrahim, Muslimin. 2016. "Readability Of Textbook Based On Activity Biology Ranging Topic For X Grade In Senior High School". Berkala Ilmiah Pendidikan Biologi. Vol.5, No.3.

Insyasiska, D., Zubaidah, S., \& Susilo, H. 2017. “Pengaruh Project Based Learning Terhadap Motivasi Belajar, Kreativitas, Kemampuan Berpikir Kritis, Dan Kemampuan Kognitif Siswa Pada Pembelajaran Biologi". Jurnal pendidikan biologi. Vol.7, No. 1, pp 9-21.

Ma'rifah, Elfa., Parno., Nandang. M., 2016. “Identifikasi Kesulitan Siswa Pada Materi Suhu Dan Kalor". Vol.4, No.5, pp 768-776.

Malycha, Charlotte P., Gunter W Maier., 2017. "The Random-Map Technique : Enhancing Mind-Mapping With A Conceptual Combination Technique To Foster Creative Potential". Creativity Research Journal. Vol. 29, No. 2, pp 114-124.

Mulyasa. 2006. Menjadi Guru Profesional Menciptakan Pembelajaran Kreatif dan Menyenangkan. Bandung: PT Remaja Rosdakarya.

Munandar, Utami. 2014. Pengembangan Kreativitas Anak Berbakat. Jakarta: PT Rineka Cipta.

Muslich, M. 2010. “Text Book Writing: Dasar-Dasar Pemahaman, Penulisan, Dan Pemakaian Buku Teks". Jogyakarta: Ar-Ruzz Media. 
Sholahuddin, Arif. 2011. “Pengaruh Buku Ajar Kimia Kelas X Berbasis Redukdi Didaktik: Uji Kelayakan Di SMA Negeri Kota Banjarmasin". Jurnal Pendidikan Dan Kebudayaan. Vol.17, No. 2.

Suparman, M. A. (2012). Desain Instruksional Modern. Jakarta: Erlangga.

Suttrisno, S., \& Puspitasari, H. (2021). Pengembangan Buku Ajar Bahasa Indonesia Membaca dan Menulis Permulaan (MMP) Untuk Siswa Kelas Awal. Tarbiyah Wa Ta'lim: Jurnal Penelitian Pendidikan dan Pembelajaran, 8(2), 83-91. 